\title{
Epidemiological and clinical burden associated with plexiform neurofibromas in pediatric neurofibromatosis type-1 (NF-1): a systematic literature review
}

\author{
Ike Iheanacho ${ }^{1}$ (1) $\cdot$ Hyun Kyoo Yoo $^{2} \cdot$ Xiaoqin Yang $^{3} \cdot$ Sophie Dodman ${ }^{1} \cdot$ Rachel Hughes $^{1} \cdot$ Suvina Amin $^{2}$
}

Received: 1 February 2021 / Accepted: 28 May 2021 / Published online: 18 June 2021

(c) The Author(s) 2021

\begin{abstract}
Purpose Patients with neurofibromatosis type-1 (NF-1) and associated plexiform neurofibromas (PNs) often have a high burden of illness owing to debilitating symptoms of these tumors and limited management options. To investigate this complex disease, a systematic literature review (SLR) was conducted on the epidemiology of pediatric NF-1 and associated PNs, the burden of illness, and outcomes of surgical resection of these tumors.

Methods Searches of MEDLINE and Embase (from database inception to October 2019) and conference proceedings (2017-2019) were performed to identify relevant studies. The review methodology was informed by the Preferred Reporting Items for Systematic Reviews and Meta-Analyses guidelines.

Results Twenty studies were identified. Evidence confirmed NF-1 is rare but that occurrence may differ geographically. Only limited data on the birth incidence of NF-1 were identified. Prevalence estimates for pediatric NF-1 varied from one per 960 individuals (aged 17 years) to one per 5681 children (aged < 16 years) across five large registry/surveillance studies (each involving $>19,000$ individuals). The prevalence of associated PNs was 0-29.6\%. PNs carried increased mortality risk in pediatric NF-1 in both studies that explored this potential association. Patients with PNs reported high use of analgesics. The complication rate post-surgery for PNs was around 17-19\%. The recurrence rate (18-68\%) was dependent on the extent of excision achieved during surgery.

Conclusions Data suggest NF-1 is a rare disease with increased morbidity and mortality in children with associated PNs. Surgical outcomes for PNs are often poor. These findings suggest significant unmet needs in patients with NF-1-associated PNs.
\end{abstract}

Keywords Neurofibromatosis type-1; Plexiform neurofibroma $\cdot$ Pediatric $\cdot$ Burden $\cdot$ Epidemiology

Ike Iheanacho

ike.iheanacho@evidera.com

Hyun Kyoo Yoo

HyunKyoo.Yoo@AstraZeneca.com

Xiaoqin Yang

xiaoqin.yang@merck.com

Sophie Dodman

sophie.dodman@evidera.com

Rachel Hughes

rachel.hughes@evidera.com

Suvina Amin

suvina.amin@astrazeneca.com

1 Evidence Synthesis, Modeling and Communication, Evidera, The Ark, 201 Talgarth Rd, London W6 8BJ, UK

2 AstraZeneca, Gaithersburg, MD 20871, USA

3 Merck \& Co., Inc, Kenilworth, NJ, USA

\section{Introduction}

Neurofibromatosis type-1 (NF-1) is an autosomal-dominant genetic disease (caused by sporadic mutations in $50 \%$ of cases [1]) characterized by the development of multisystem tumors [2], particularly neurofibromas-benign nerve sheath tumors that can cause pruritus, pain, sensory impairment, and motor dysfunction [3]. Other NF-1 manifestations include abnormal skin pigmentation, iris Lisch nodules, skeletal abnormalities, cardiovascular complications, and learning difficulties $[3,4]$. Typically, these features begin in early childhood. For example, one study found the proportion of sporadic NF-1 cases that met the National Institutes of Health (NIH) Diagnostic Criteria was around one-half by 1 year of age and $97 \%$ by 8 years [2].

Individuals with NF-1 are also at an increased risk of developing other tumors [3, 4]. In particular, an estimated 
30-50\% develop plexiform neurofibromas (PNs) [3], which involve multiple nerve fascicles and can transverse the length of nerves. These lesions can cause pain, disfigurement, bone destruction, and compression of vital structures [5], features that begin in early childhood and progress throughout life [6]. In addition, PNs may undergo transformation to malignant nerve sheath tumors (MPNST) [3]. Estimates suggest that $8-13 \%$ of NF-1 patients develop such lesions during their lifetime, although some of these tumors occur in the absence of pre-existing PNs [7].

Current management guidelines for NF-1 and PNs focus on continuously monitoring patients for the development or progression of clinical features, such as pain [2, 3]. For tumor progression, surgical resection is considered the standard of care. However, surgery carries risks, may not offer definitive treatment (e.g., if complete excision is impossible), and may be followed by recurrence $[2,3,8]$.

Consequently, patients with NF-1-associated PNs may have considerable unmet needs, related to disabling symptomatology and limited management options. Understanding and addressing any such needs in children is crucial, given NF-1 is a developmental and progressive disorder, with morbidity and mortality that may differ across age groups. However, there is a lack of published, collated evidence characterizing various aspects of this disease burden. Targeting these data gaps, this systematic literature review (SLR) aimed to synthesize published evidence on epidemiological outcomes for pediatric NF-1 and NF-1-associated PNs, on pain related to PNs, and on outcomes of surgery to resect or debulk PNs.

\section{Methods}

The methodology for this SLR was informed by standards in the Preferred Reporting Items for Systematic Reviews and Meta-Analyses (PRISMA) guidelines [9].

\section{Literature searches and data sources}

Searches were conducted in Embase and MEDLINE via OvidSP in October 2019 using a strategy that combined terms (free-text keywords and controlled subject headings) for relevant populations (patients with NF-1/NF-1-associated PNs) with terms for the topics of interest (epidemiology; pain; surgery), without publication date limits. Further details on the searches are presented in the Online Resource. Also, recent proceedings (from 2017-2019) of selected conferences were searched for relevant evidence that had not yet been published in peer-reviewed journals.

\section{Study selection}

Studies were screened for inclusion against the pre-defined population, interventions, comparators, outcomes, and study design (PICOS) criteria in Table 1. To be eligible, studies had to have (1) investigated epidemiological outcomes in children (aged $\leq 18$ years) with NF-1, and/or (2) evaluated pain or surgical outcomes associated with $\mathrm{PNs}$ in pediatric NF-1. No geographic or temporal exclusion criteria were applied. All abstracts and full-text articles were screened by two independent investigators, with any conflicts resolved by a third investigator.

\section{Data extraction and synthesis}

Data were extracted by one investigator and then validated by a second investigator. A third investigator was consulted to resolve any disagreements. For added quality assurance, final checks of all extracted data were conducted, to ensure consistency in how this information was captured from publications.

Results were collated and assessed by using qualitative synthesis. Specifically, studies were grouped according to key themes identified, and the connections between studies and the objectives of the review were noted, interpreted, and summarized accordingly. No formal risk-of-bias assessment was conducted because the disparate nature of study designs included in the review precluded the use of a single standard recognized tool for such analysis. However, study sample sizes and data sources were considered as broad determinants of study quality, under the assumption that larger, population-based or multicenter studies were more likely to provide robust and generalizable results than were smaller studies.

\section{Results}

\section{Study selection}

The database searches yielded 2688 articles, 18 of which met the study selection criteria. Another four articles were identified through supplementary searches, resulting in 22 included publications on 20 unique studies (Fig. 1).

\section{Overview of study characteristics}

Of the 22 publications identified, 14 (64\%) reported on the epidemiology of NF-1 or PN in NF-1 [10-23]. One epidemiology study also reported on the burden of pain and outcomes for patients undergoing PN surgery (Fig. 2) [23]. 
Table 1 PICOS criteria

\begin{tabular}{|c|c|c|c|}
\hline Domain & Epidemiology & Burden of pain & Burden of surgery \\
\hline Population & $\begin{array}{l}\bullet \text { Pediatric patients (aged } \leq 18 \text { years) }{ }^{\mathrm{a}} \\
\text { with NF-1 }\end{array}$ & $\begin{array}{l}\text { - Pediatric patients (aged } \leq 18 \text { years) } \\
\text { with NF-1 }\end{array}$ & $\begin{array}{l}\text { - Pediatric patients (aged } \leq 18 \text { years) } \\
\text { with NF-1 }\end{array}$ \\
\hline Intervention & - None required & - None required & - Surgical interventions \\
\hline Comparators & - None required & - Any or none required & - Any or none required \\
\hline Outcomes & $\begin{array}{l}\text { - Incidence } \\
\text { - Prevalence } \\
\text { - Mortality }\end{array}$ & $\begin{array}{l}\text { - Incidence of pain } \\
\text { - Prevalence of pain } \\
\text { - Pain intensity } \\
\text { - Functional outcomes and mobility } \\
\text { outcomes related to pain } \\
\text { - Real-world treatment outcomes for } \\
\text { pain } \\
\text { - Humanistic outcomes in pain (includ- } \\
\text { ing HRQoL, effects on sleep, and } \\
\text { psychological outcomes) } \\
\text { - Economic outcomes (healthcare } \\
\text { resource use and costs) associated } \\
\text { with pain }\end{array}$ & $\begin{array}{l}\text { - Indication for surgery } \\
\text { - Operation rates } \\
\text { - Complete and partial resection rates } \\
\text { - Tumor recurrence rate following } \\
\text { surgery } \\
\text { - Secondary surgery rates } \\
\text { - Bleeding complications } \\
\text { - Wound healing complications } \\
\text { - Post-operative HRQoL } \\
\text { - Neurological complications }\end{array}$ \\
\hline Study design & $\begin{array}{l}\text { - Retrospective and prospective, obser- } \\
\text { vational studies } \\
\text { - Cross-sectional studies } \\
\text { - SLRs }\end{array}$ & $\begin{array}{l}\text { - Clinical trials } \\
\text { - Retrospective and prospective, obser- } \\
\text { vational studies } \\
\text { - Cross-sectional studies } \\
\text { - SLRs }\end{array}$ & $\begin{array}{l}\text { - Clinical trials } \\
\text { - Retrospective and prospective, } \\
\text { observational studies } \\
\text { - Cross-sectional studies } \\
\text { - SLRs }{ }^{\text {b }}\end{array}$ \\
\hline Search limits & & & \\
\hline Publication date & \multicolumn{3}{|l|}{ No time limit specified } \\
\hline Publication type & \multicolumn{3}{|c|}{ Full-text publications and conference abstracts } \\
\hline Geographical region & \multicolumn{3}{|l|}{ No limit } \\
\hline Language & \multicolumn{3}{|c|}{ No limit in searches, but only English-language publications are included in the review } \\
\hline
\end{tabular}

${ }^{a}$ Studies that enrolled adults and children with NF-1 were eligible for inclusion if the study reported separate subgroup data for pediatric patients ${ }^{b}$ Bibliographies of relevant SLRs/meta-analyses identified by the database searches were hand-searched for any additional, potentially relevant studies Abbreviations: $\mathrm{HRQoL}=$ health-related quality of life; $\mathrm{NF}-1=$ neurofibromatosis type 1 ; PICOS = population, interventions, comparators, outcome, study design; $\mathrm{PN}=$ plexiform neurofibroma; $\mathrm{SLR}=$ systematic literature review

Fig. 1 PRISMA diagram. Abbreviations: PRISMA, Preferred Reporting Items for Systematic Reviews and MetaAnalyses; SLR, systematic literature review

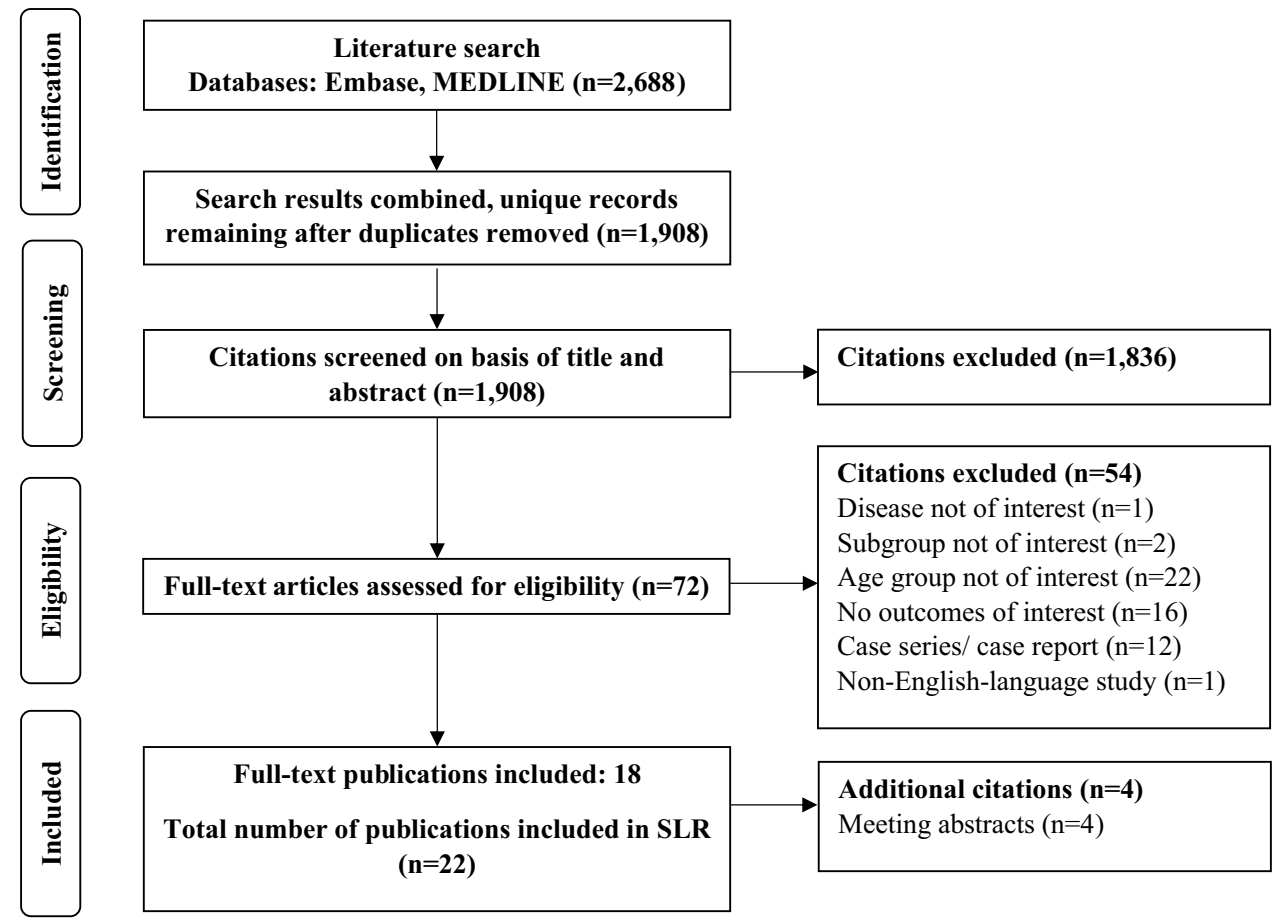


Fig. 2 Overview of the outcomes reported in included studies. *Studies report tumor recurrence

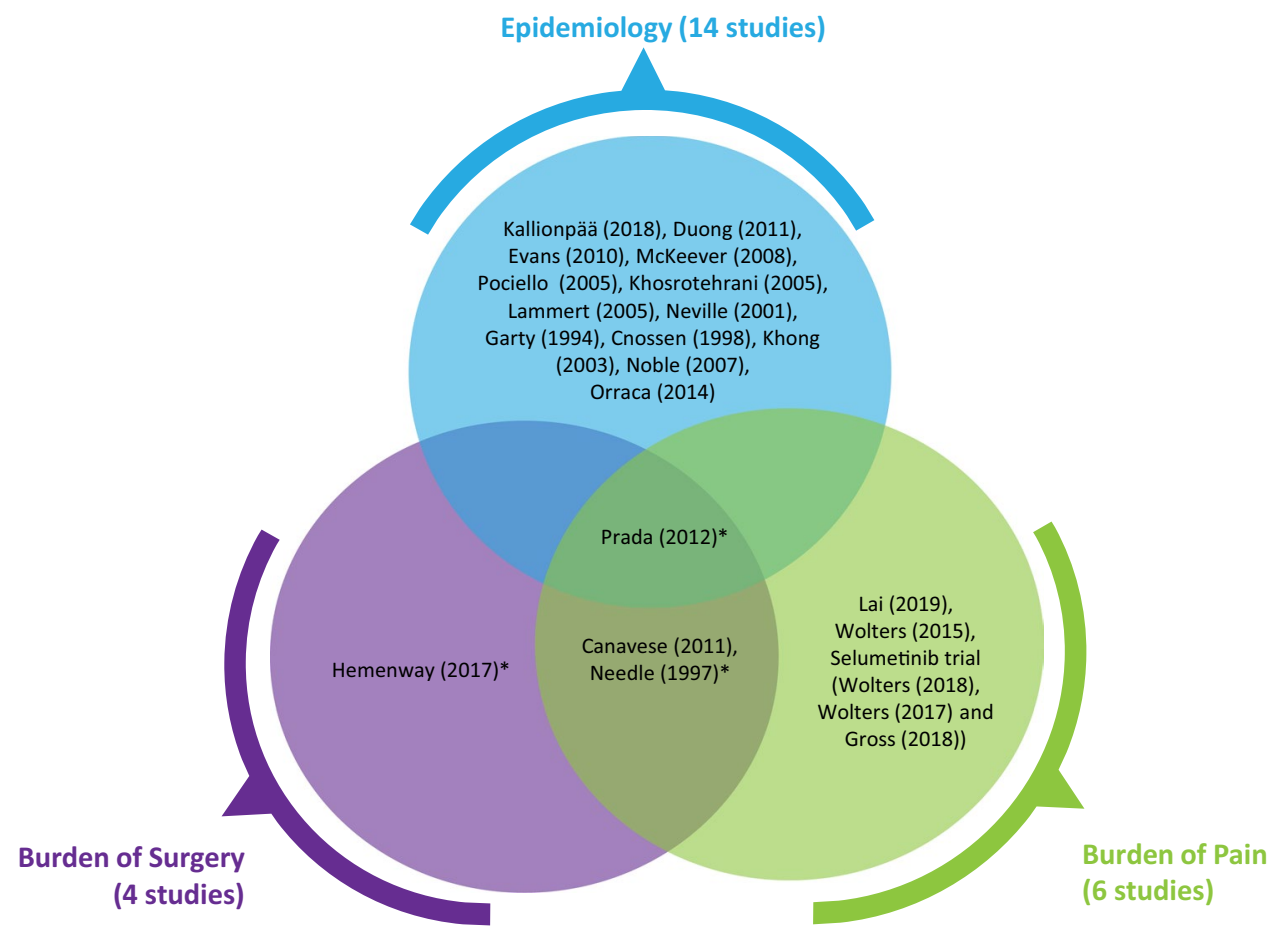

In total, four studies reported on the burden of PN-related surgery [23-26], and six unique studies (eight publications) examined the burden of pain in this population.

Two epidemiology studies were conducted in the United Kingdom (UK) [12, 18], two in the United States (US) [19, 23], and one in each of following locations: Australia [20], Cuba [21], Finland [14], France [11], Germany [17], Israel [13], Italy [22], the Netherlands [10], North America [10, 16], and Hong Kong [15]. All studies reporting on pain associated with PNs and outcomes of PN surgery were US based [23, 25-31] (Table 2).

\section{Epidemiology}

Across the 14 studies providing data on the epidemiology of NF-1, there was only limited evidence (two studies) on the birth incidence of NF-1. Six studies presented prevalence estimates for NF-1 in general. Two studies compared mortality rates in NF-1 patients with and without associated PNs. Overall, the available global epidemiology evidence confirmed that NF-1 is a rare condition but with an occurrence that may differ markedly across countries [10-23]. It also showed that PNs are both common [10, 15, 16, 18, 20, 23 ], and potentially life-limiting in pediatric cases [16, 23] (Table 3).

One of the two studies reporting birth incidence estimates, a population-based registry analysis [12] in the UK $(n=3,050,409)$, found a median rate of one per 3657 people [12]. The second, much smaller, and therefore potentially less representative, Italian school-based surveillance study $(n=2513)$ estimated a birth incidence of one case per 400 births [22].

Estimates of the prevalence of NF-1 [13, 14, 17, 18, 21, $22]$ generally varied with study size. Similar to birth incidence, the highest prevalence estimate-one case per 264 children (aged 6 years old)_-was from a small school-based study in Italy [22]. By comparison, three surveillance studies (from Cuba [21], Germany [17], and Israel [13]) with sample sizes between 19,404 and 152,819 children, and a population-based registry study (from Finland [14]), found lower estimates: from one case per 960 individuals [13] to one per 2996 individuals [17]. When examining prevalence by country, the two studies reporting the highest prevalence overall were the school-based study (from Italy) [22] and a review of military recruits (aged 17 years, from Israel) [14]. The lowest prevalence estimate of one per 5681 children was from a large database study in Northern Ireland that identified $75 \mathrm{NF}-1$ patients referred to a medical genetics center for evaluation, among the overall population of 425,250 individuals aged under 16 years [18].

Estimates of the prevalence of PNs in children with NF-1 from seven available studies [10, 15, 16, 18, 20, 21, 23] ranged from 0 [21] to $29.6 \%$ [23]. The variation in estimates may be due to study heterogeneity, in particular, difference in sample sizes. The two studies $[15,21]$ reporting the lowest prevalence, $0 \%$ and $5.7 \%$, enrolled only 17 and 53 patients, respectively. Among studies with larger sample sizes (over 150 patients), and hence potentially greater reliability and generalizability, the prevalence of PNs ranged from 9.04 to $29.6 \%$ [10, 16, 23]. A trend toward higher prevalence in 


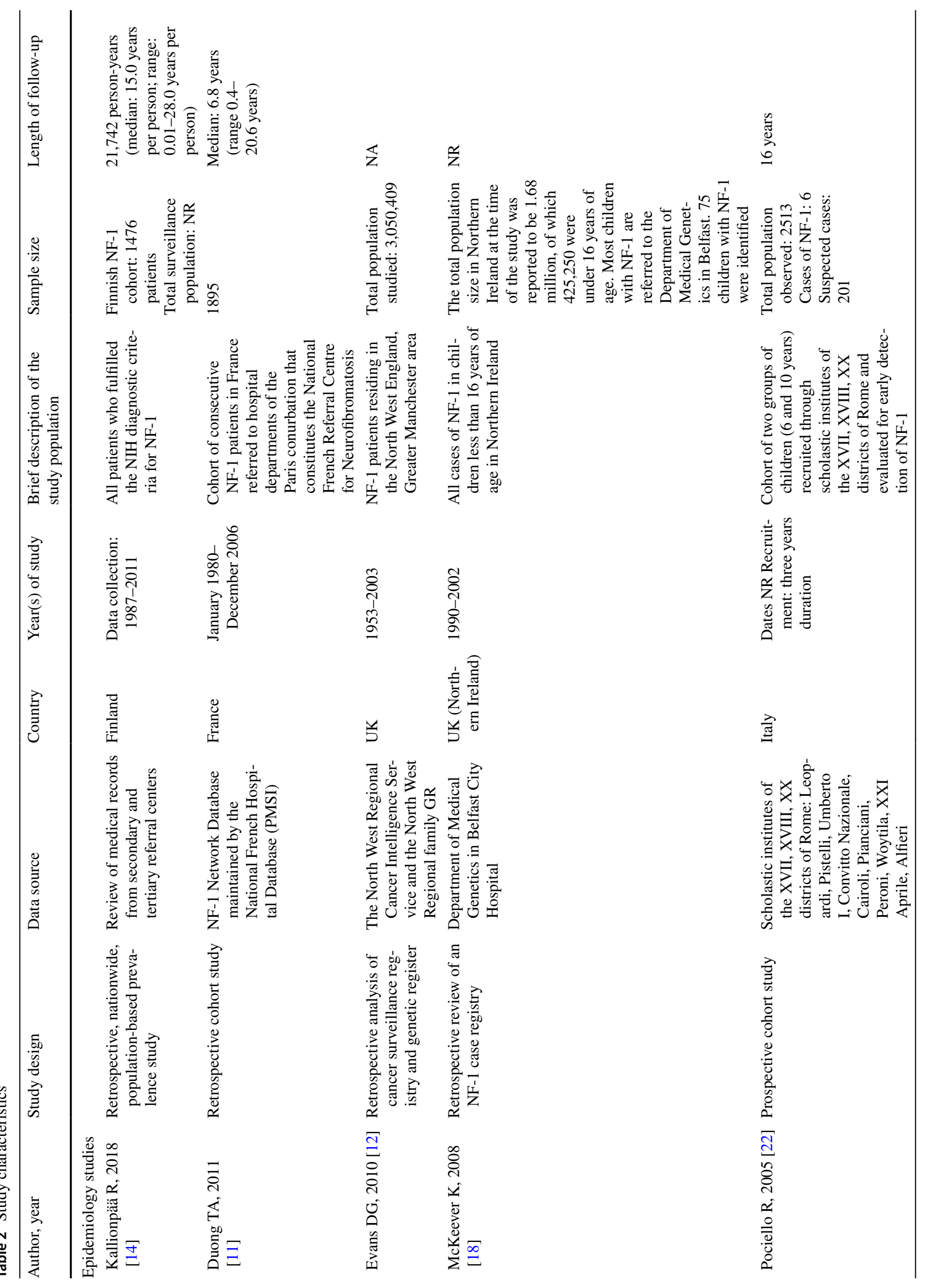




\begin{tabular}{|c|c|c|c|c|c|c|c|}
\hline 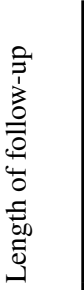 & 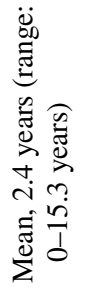 & 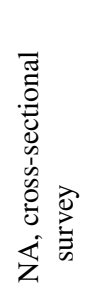 & 号 & 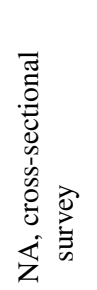 & \multicolumn{3}{|c|}{ 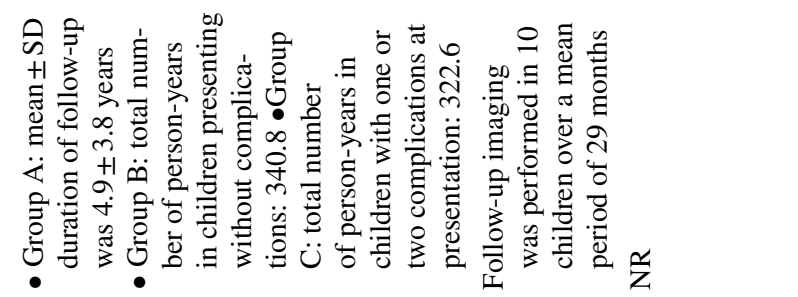 } \\
\hline 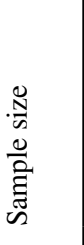 & $\ddot{q}$ & 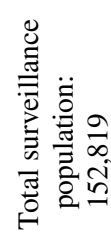 & ̀ & 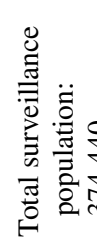 & & $n$ & $\bar{\beth}$ \\
\hline 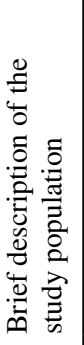 & 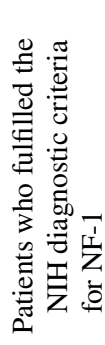 & 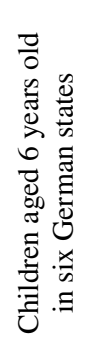 & 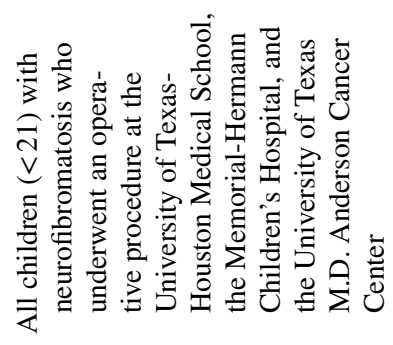 & 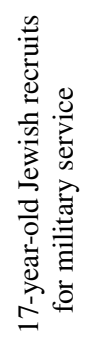 & 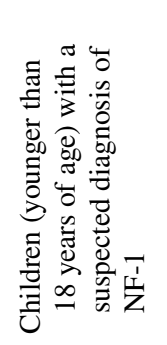 & 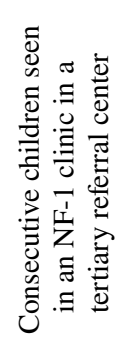 & 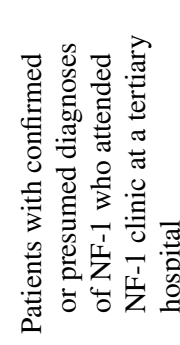 \\
\hline 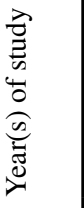 & & 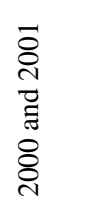 & $\begin{array}{l}\stackrel{a}{a} \\
\frac{1}{2} \\
\hat{a}\end{array}$ & 孚 & $\begin{array}{l}2 \\
2 \\
\vdots \\
2 \\
\infty \\
2\end{array}$ & 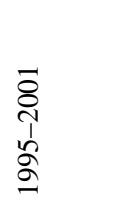 & 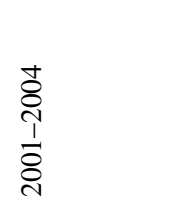 \\
\hline & 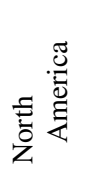 & 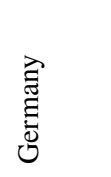 & 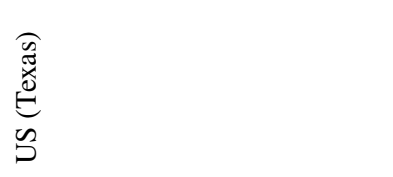 & $\begin{array}{l}\overrightarrow{\mathbb{\Xi}} \\
\stackrel{\mathscr{a}}{a}\end{array}$ & 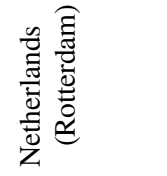 & $\begin{array}{l}00 \\
\overline{0} \\
0 \\
000 \\
0 \\
0 \\
0\end{array}$ & 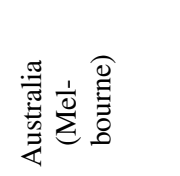 \\
\hline & 至 & 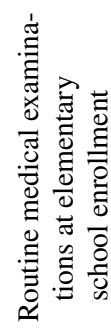 & 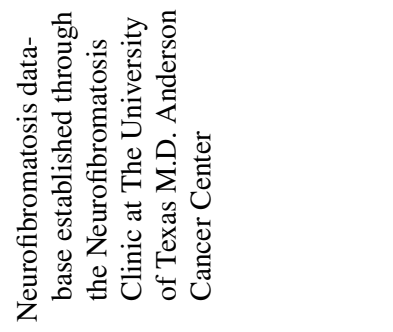 & 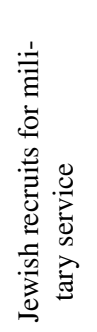 & 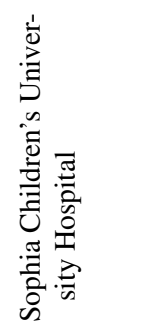 & 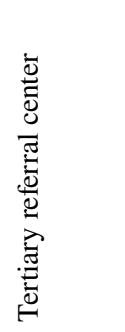 & 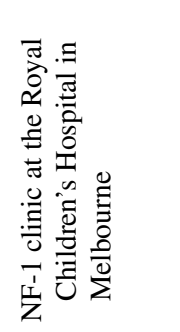 \\
\hline 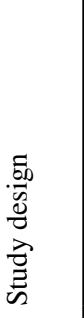 & 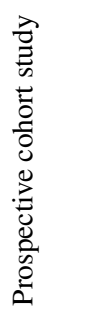 & 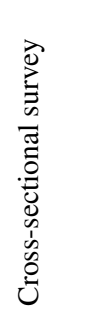 & 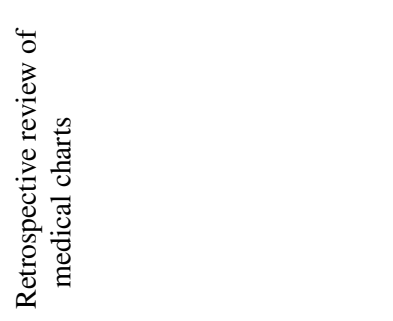 & 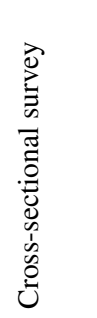 & $\begin{array}{l}\text { के } \\
\overline{0} \\
0 \\
0 \\
0 \\
0 \\
0 \\
0 \\
: \\
0 \\
0 \\
0 \\
0 \\
0 \\
0\end{array}$ & 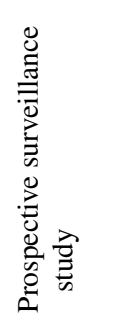 & 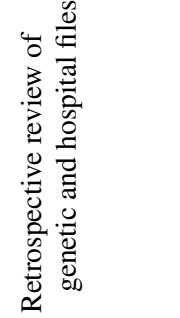 \\
\hline 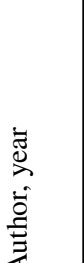 & 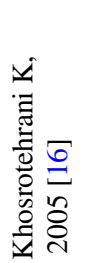 & 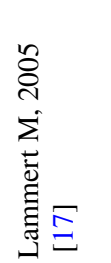 & 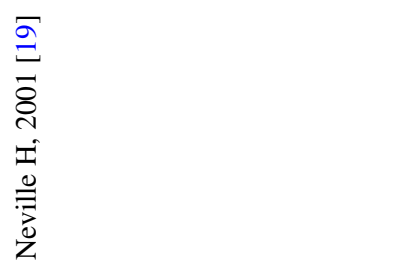 & 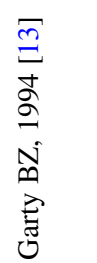 & 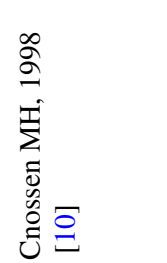 & 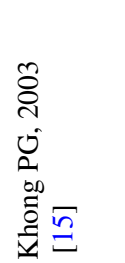 & 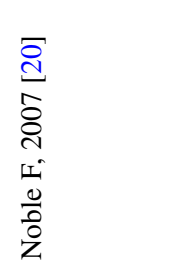 \\
\hline
\end{tabular}




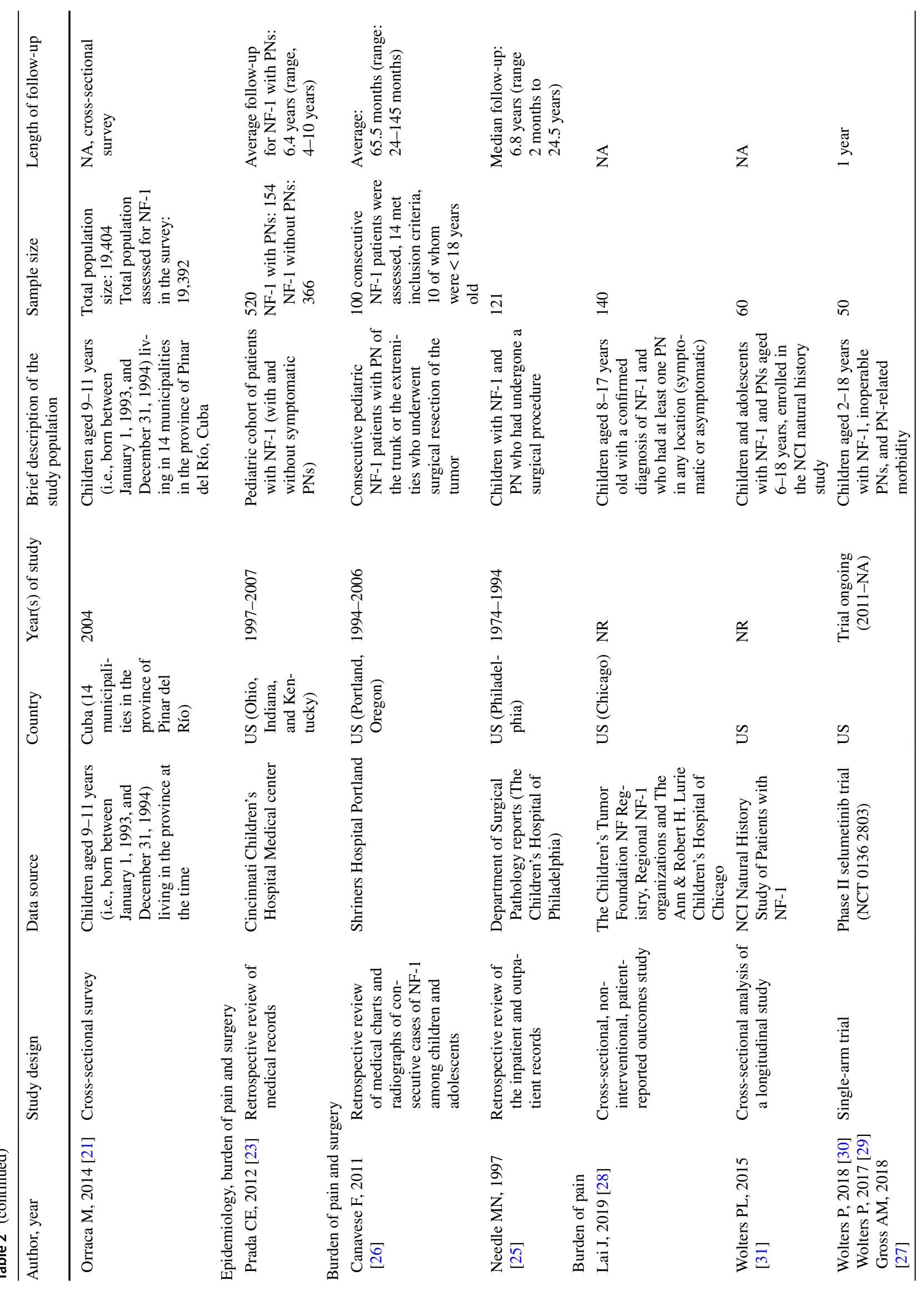




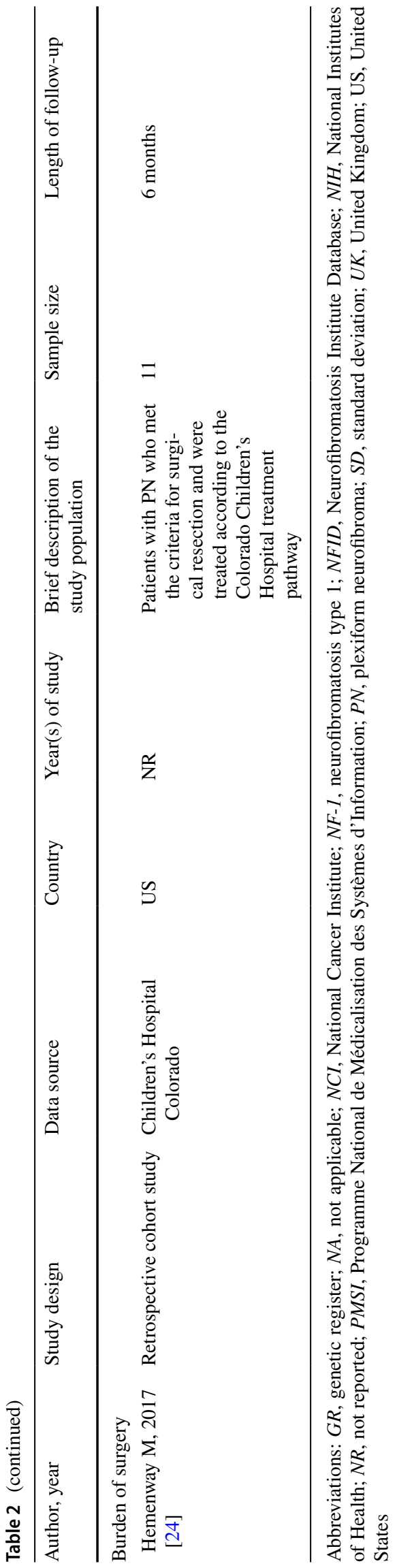

older populations was observed in one study, which reported that PNs affected $10.3 \%, 22.9 \%$, and $27.8 \%$ of patients aged 0 to 10 years, 10 to 20 years, and $>20$ years, respectively [20].

Evidence from two studies indicated that PNs carry an increased mortality risk in pediatric NF-1 [16, 23]. A prospective study of 405 children (aged $<17$ years) with NF-1, conducted in North America, compared the clinical features of those that died during follow-up (mean duration 2.4 years) and those that survived and found that facial PNs were a significant mortality risk factor according to univariate analysis (reported p-value $=0.05$ ) [16]. Similarly, a US retrospective study reported that, compared to patients with NF-1 without PNs or with asymptomatic, undetected PNs, those with symptomatic PNs had a higher mortality rate (3.2\% vs. $0.5 \%, p=0.024)$, over an average follow-up of 6.4 years [23]. However, no specific definition of "symptomatic" was given in the study report.

\section{Burden of pain}

Among the studies examining baseline PN-related complications, pain was the most consistently reported problem $[5,25,28,32,33]$. Pain-related outcomes were reported in six unique studies: three retrospective analyses [23, 25, 26], two cross-sectional analyses [28, 31], and the phase II selumetinib trial (NCT01362803) [27, 29, 30]. Study sample sizes ranged from $50[29,30,32]$ to 520 patients [23]. The pain outcomes reported varied across publications, covering, for example, the proportion of patients with PNs who experienced pain, pain reported as an indication for surgery, pain intensity (measured using various scales), and pain management. Collectively, the studies indicated that PN-related pain is common, often considerable, and potentially difficult to manage.

Five studies examined the proportion of patients with NF1 -associated PNs who experienced pain or how commonly PN-related pain was an indication for surgery $[23,25,26$, $28,30]$. One observational study found $67.1 \%$ of patients had PN-related pain [28]. The selumetinib trial reported that $70 \%$ of patients had pain at baseline [30]. Also, three studies reporting the proportion of PNs for which pain was an indication for subsequent surgery found this was 9.5\% (16/168) of tumors in one study [25], over 18.8\% ( $\geq 18 / 96$ patients) in another [23], and $100 \%$ in a retrospective study of only 16 lesions operated on in a single institution [26].

Pain intensity was reported in three studies, each evaluating this outcome with a different tool. One study assessed pain interference using the Impact of Pediatric Illness (IPI) scale [31] for patients aged 6-18 years (by caregiver proxy rating) and adolescents aged 10-18 years (self-rating). It found the following results for these two groups: "no pain" (27\% and $41 \%$, respectively), "little pain" (22\% and $22 \%$ ), 
"some pain" (34\% and 22\%), "much pain" (15\% and 10\%), and "a lot of pain" (2\% and 5\%), respectively. Similarly, another study reported that $31 \%$ of pediatric patients had mild, $24 \%$ moderate, and $15 \%$ severe tumor pain, although it was unclear which scale was used to gather these data [30]. The third study reported that pain intensity among patients [28] assessed using the Patient-Reported Outcomes Measurement Information System (PROMIS; mean \pm standard deviation: $49.75 \pm 13.4$ ) was not significantly different from a normative sample $(50 \pm 10)$. However, $67 \%$ of the children in this study reported pain, and the authors also noted considerable variation in the pain interference scores and suggested the substantial pain interference some patients experienced was "averaged out" by results for those with no pain.

Only one identified study assessed management of PNrelated pain [31]. In this retrospective, US-based analysis, $33 \%$ of patients reported regular pain medication use: $3 \%$ using over-the-counter (OTC) medication (acetaminophen, ibuprofen) and 30\% taking prescription medication (with/ without OTC medication). Among those taking prescribed treatments, $61 \%$ reported being on anticonvulsants, $39 \%$ opioids, $33 \%$ antidepressants, and $17 \%$ using topical/ local anesthetics [31].

\section{Burden of surgery}

Evidence on the clinical outcomes associated with surgery for PNs was reported by four studies [23-26]. Each of these involved reviewing medical records from a single institution in the US and had small sample sizes (11 [24] to 154 patients [23]). Pain was frequently reported as a reason for surgery [23-26], and other common indications included neurological deficits [23], loss of functionality [24], airway compression [23], and physical disfigurement or cosmetic reasons [23, 25, 26]. Minimal detail of surgical procedures and target PNs was reported, with a lack of information on such characteristics as the nature of PNs, their size, and their degree of vascularization. Data across the four studies indicated that surgery carries considerable risks, including high chances of tumor recurrence [23-26], even following complete excision [25].

All four studies reported on operation rates. The largest study $(n=154)$ provided rates for patients with NF-1 with associated PNs aged between 0 and 12 years [23]. Among these individuals, $62.3 \%$ with PNs underwent surgery during an average follow-up of 65.5 months. The three smaller studies reported operation rates per lesion, which ranged from 1.3 to 1.8 surgeries $[23,25,26]$. The studies did not report on whether there was any association between age and operation rates. One study reported the extent of resection achieved during surgery, as follows: gross total resection (15\%), near-total resection (23\%), and subtotal resection
(44\%) [25]. Secondary surgery rates were $43 \%$ of patients and $44 \%$ of lesions, as reported in two studies [23, 33].

Three of the studies on surgery also analyzed rates of post-operative complications [23, 25, 26], which ranged from $4.6 \%$ [25] of patients experiencing permanent neurological deficit to $18.8 \%$ [26] with wound-healing complications. Tumor recurrence (assessed in three studies) was also common, with the rate depending on the extent of tumor excision achieved. Specifically, recurrence rates across two studies [23, 25] ranged from 54.9 to $67.7 \%$ for partially resected tumors ( $<50 \%$ excision); $28.8 \%$ to $44.6 \%$ following subtotal resections (defined as $50 \%$ to $80 \%$ or $90 \%$ excision); $39.5 \%$ following near-total resections ( $>90 \%$ removal); and $20 \%$ for completely excised tumors. The third study involved only 11 patients and reported an $18 \%$ recurrence rate [24].

\section{Discussion}

The evidence collated in this SLR demonstrates that children with NF-1-associated PNs experience substantial disease burden with significant unmet needs. It is important to note, however, the volume of identified literature on NF1-associated PNs was limited, perhaps suggesting a lack of awareness and understanding of the condition in general and of the particular problems faced by patients with NF1-associated PNs.

In general, the available prevalence estimates indicate that pediatric NF-1 is rare. However, there was considerable variation in the data across studies. The identified epidemiology studies were heterogeneous with regard to key characteristics, including variation in sample sizes (and therefore, possibly, the generalizability of any findings), differences in the age groups studied [34], and study procedures (e.g., case detection methods). Some evidence also suggested trends toward lower rates in northern European countries [14, 17, 18] than in the other regions for which data are available, although the evidence for this trend is very limited.

Similarly, clinical studies have reported wide-ranging estimates of the prevalence of PNs in NF-1, reaching up to $50 \%$. However, the real-world studies identified in the review suggest that the prevalence of NF-1-associated PNs ranged between 0 and 30\%. Definitive conclusions for the discrepancy between estimates from real-world analyses and those from other study types cannot be drawn on the data available. However, detection of internal or asymptomatic PNs through imaging modalities may have contributed to the higher estimates seen in clinical interventional studies. Additionally, higher prevalence estimates are likely to be reported in studies specifically focused on the identification of PNs. Furthermore, disease severity may be worse in patients evaluated in clinical studies or might differ due to 


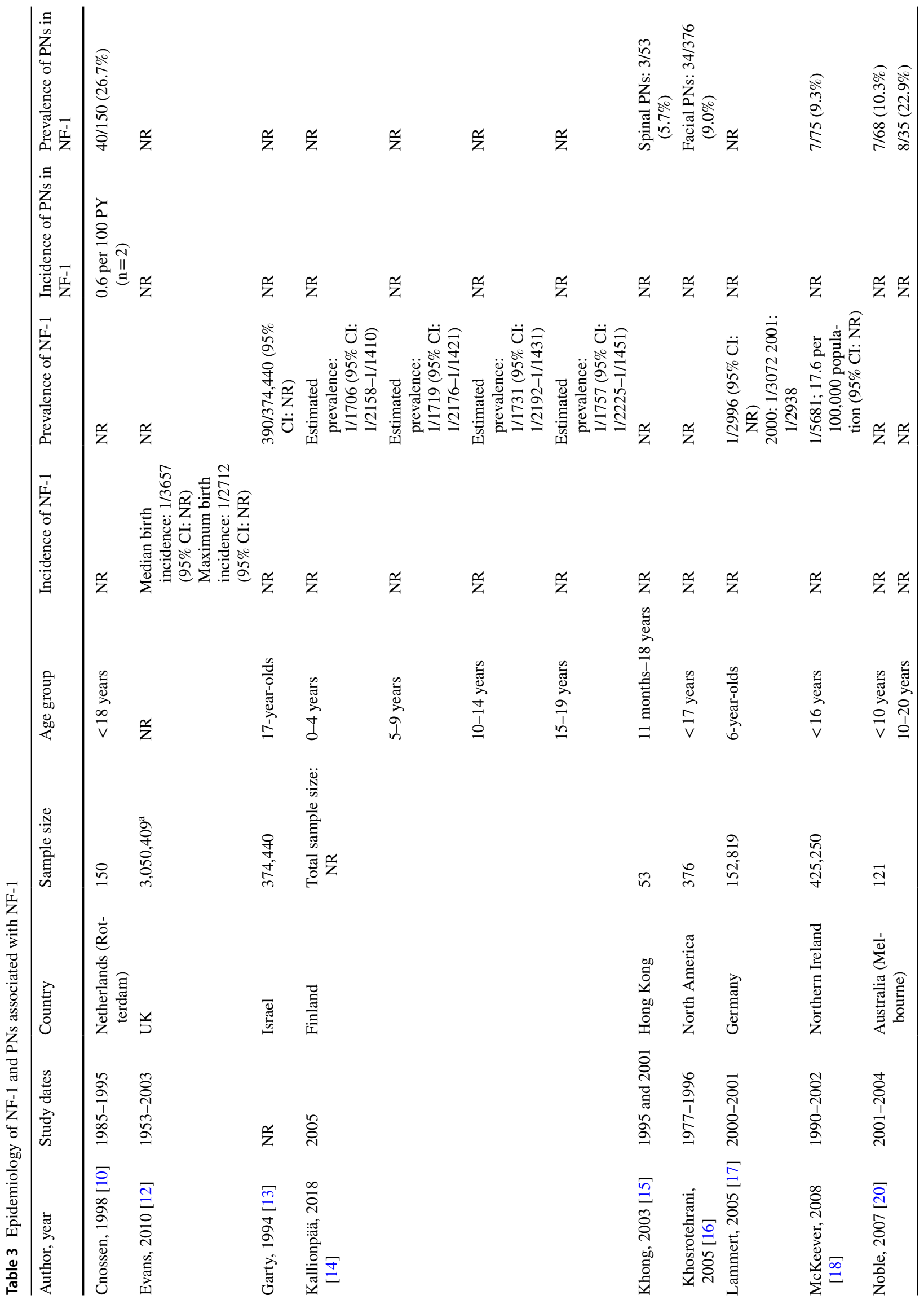


study selection criteria, such that their results may not be generalizable to real-world populations.

The identified literature shows that PNs are often painful, with only a minority of patients (typically under $30 \%$ ) reporting not having this symptom [30,31]. Several studies evaluated the intensity of pain associated with PNs [28, 30, 31]; however, each used a different instrument, suggesting a lack of consensus on the most appropriate tool to assess PN-related pain in this population. Accordingly, the use of medication [31] for pain relief for these tumors is common and sometimes involves opioid treatment. Surgical resection of tumors is often performed for painful PNs but data in this review indicate considerable limitations of such therapy.

Details on the surgical procedures undertaken were inconsistently reported across the included studies. Nevertheless, it is clear from the available data that surgery carries a high risk of post-operative problems, including complications such as poor wound healing [26]. Furthermore, tumors may be unamenable to complete surgical excision due to their extent and/or location [25]. Also, recurrence is very common post-surgery [23-25], with even total excision of PNs being associated with around a $20 \%$ chance of this outcome [25], often resulting in the need for subsequent operations $[23,25,26]$. The evidence identified provided no clear insights into whether the rate of recurrence was associated with age.

\section{Strengths and limitations}

The SLR was informed by the quality standards in the PRISMA guidelines [35] so it included clear documentation of the review methodology, search strategy and yields, and study attrition. Study selection criteria targeted publications that would best address the pre-defined research objectives and questions.

To our knowledge, no previously published SLR has investigated the epidemiology of NF-1 or systematically analyzed data on the burden of pain or surgical outcomes related to NF-1 with PNs. Therefore, this study addressed an evidence gap, using a systematic approach to synthesize the available evidence on these topics. It highlights the limited availability and heterogeneity of evidence on epidemiological outcomes and the lack of high-quality data on the burden of pain and surgery associated with PNs.

Most of the available evidence for these topics was retrospective, which increases its risk-of-bias compared with data generated by prospective study designs [36]. For some topics, the review relied on subgroup data reporting outcomes for the population of interest. Often, this meant that the primary objectives and overall conclusions of the individual studies were not specific to the focus of this SLR. The limited number of epidemiology estimates and the lack of global data on the burden of pain from real-world settings 
specifically highlight the need for further research on these topics.

\section{Conclusion}

The identified evidence indicates that while NF-1 is a rare disease, up to around one-third of patients have PNs, and that these tumors can cause high morbidity. Surgical excision or resection of PNs carries considerable risk and is associated with a high rate of tumor recurrence. Overall, these findings suggest a need for better management options to minimize the disease burden in patients with NF-1-associated PNs.

Supplementary Information The online version contains supplementary material available at https://doi.org/10.1007/s10072-021-05361-5.

Acknowledgements The authors wish to thank Caroline Cole, Manager in Editorial Design and Services at Evidera, for the medical writing support she provided during the development of this article.

Author contributions All authors were involved in the design and conception of the study. All authors revised critically and approved the final version for publication and meet the following four criteria for authorship recommended by the International Committee of Medical Journal Editors (ICMJE): (1) substantial contributions to the conception and design of the work; (2) drafting the work or revising it critically for important intellectual content; (3) final approval of the version to be published; and (4) agreement to be accountable for all aspects of the work in ensuring that questions related to the accuracy or integrity of any part of the work are appropriately investigated and resolved.

Funding AstraZeneca/Merck Sharp \& Dohme Corp., a subsidiary of Merck \& Co., Inc., Kenilworth, NJ, USA, provided the funding for the study and for the manuscript.

Data availability Not applicable.

Code availability Not applicable.

\section{Declarations}

Ethics approval Not applicable: the study did not involve conducting research on humans, being based entirely on analysis of already published data, for which no ethics approval was needed.

Consent to participate Not applicable: the study did not involve conducting research on humans, being based entirely on analysis of already published data, for which no consent for participation was needed.

Consent for publication Not applicable: the study did not involve conducting research on humans, being based entirely on analysis of already published data, for which no consent for publication was needed.

Conflict of interest H.K.Y. and S.A. are employed by AstraZeneca and own stock. X.Y. is an employee of Merck Sharp \& Dohme Corp., a subsidiary of Merck \& Co., Inc., Kenilworth, NJ, USA, and owns stock in Merck \& Co., Inc., Kenilworth, NJ, USA. I.I., S.D., and R.H. are employed by Evidera, which provides consulting and other research services to pharmaceutical, medical device, and related organizations.
In their salaried positions, they work with a variety of companies and organizations and are precluded from receiving payment or honoraria directly from these organizations for services rendered. Evidera received funding from AstraZeneca and Merck Sharp \& Dohme Corp., a subsidiary of Merck \& Co., Inc., Kenilworth, NJ, USA, to participate in the study and to provide medical writing support for dissemination of this manuscript. All authors participated in data analysis and interpretation and contributed to the development of the manuscript.

Disclaimer All named authors meet the International Committee of Medical Journal Editors (ICMJE) criteria for authorship for this manuscript, take responsibility for the integrity of the work as a whole, and have given final approval to the version to be published.

Open Access This article is licensed under a Creative Commons Attribution 4.0 International License, which permits use, sharing, adaptation, distribution and reproduction in any medium or format, as long as you give appropriate credit to the original author(s) and the source, provide a link to the Creative Commons licence, and indicate if changes were made. The images or other third party material in this article are included in the article's Creative Commons licence, unless indicated otherwise in a credit line to the material. If material is not included in the article's Creative Commons licence and your intended use is not permitted by statutory regulation or exceeds the permitted use, you will need to obtain permission directly from the copyright holder. To view a copy of this licence, visit http://creativecommons.org/licenses/by/4.0/.

\section{References}

1. Anderson JL, Gutman DH (2015) Neurofibromatosis type 1. Handb Clin Neurol 132(3):75-86

2. Boyd KP, Korf BR, Theos A (2009) Neurofibromatosis type 1. J Am Acad Dermatol 61(1):1-14-15-16. https://doi.org/10.1016/j. jaad.2008.12.051

3. Hirbe AC, Gutmann DH (2014) Neurofibromatosis type 1: a multidisciplinary approach to care. Lancet Neurol 13(8):834-843. https://doi.org/10.1016/S1474-4422(14)70063-8

4. Korf BR (2000) Malignancy in neurofibromatosis type 1 . Oncologist 5(6):477-485. https://doi.org/10.1634/theoncolog ist.5-6-477

5. Kim A, Gillespie A, Dombi E, Goodwin A, Goodspeed W, Fox E, Balis FM, Widemann BC (2009) Characteristics of children enrolled in treatment trials for NF1-related plexiform neurofibromas. Neurology 73(16):1273-1279. https://doi.org/10.1212/WNL. 0b013e3181bd1326

6. Dombi E, Solomon J, Gillespie AJ, Fox E, Balis FM, Patronas N, Korf BR, Babovic-Vuksanovic D, Packer RJ, Belasco J, Goldman S, Jakacki R, Kieran M, Steinberg SM, Widemann BC (2007) NF1 plexiform neurofibroma growth rate by volumetric MRI: relationship to age and body weight. Neurology 68(9):643-647. https:// doi.org/10.1212/01.wnl.0000250332.89420.e6

7. Evans DGR, Baser ME, McGaughran J, Sharif S, Howard E, Moran A (2002) Malignant peripheral nerve sheath tumours in neurofibromatosis 1. J Med Genet 39:311-314

8. Gross AM, Singh G, Akshintala S, Baldwin A, Dombi E, Ukwuani S, Goodwin A, Liewehr DJ, Steinberg SM, Widemann BC (2018) Association of plexiform neurofibroma volume changes and development of clinical morbidities in neurofibromatosis 1 . Neuro Oncol 20(12):1643-1651

9. Moher D, Liberati A, Tetzlaff J, Altman DG, P Group (2009) Preferred reporting items for systematic reviews and meta-analyses: the PRISMA statement. PLoS med 6(7):e1000097 
10. Cnossen MH, de Goede-Bolder A, van den Broek KM, Waasdorp CM, Oranje AP, Stroink H, Simonsz HJ, van den Ouweland AM, Halley DJ, Niermeijer MF (1998) A prospective 10 year follow up study of patients with neurofibromatosis type 1. Arch Dis Child 78(5):408-412. https://doi.org/10.1136/adc.78.5.408

11. Duong TA, Sbidian E, Valeyrie-Allanore L, Vialette C, Ferkal S, Hadj-Rabia S, Glorion C, Lyonnet S, Zerah M, Kemlin I, Rodriguez D, Bastuji-Garin S, Wolkenstein P (2011) Mortality associated with neurofibromatosis 1: a cohort study of 1895 patients in 1980-2006 in France. Orphanet J Rare Dis 6:18. https://doi.org/ 10.1186/1750-1172-6-18

12. Evans DG, Howard E, Giblin C, Clancy T, Spencer H, Huson SM, Lalloo F (2010) Birth incidence and prevalence of tumor-prone syndromes: estimates from a UK family genetic register service. Am J Med Genet A 152A(2):327-332. https://doi.org/10.1002/ ajmg.a.33139

13. Garty BZ, Laor A, Danon YL (1994) Neurofibromatosis type 1 in Israel: survey of young adults. J Med Genet 31(11):853-857. https://doi.org/10.1136/jmg.31.11.853

14. Kallionpaa RA, Uusitalo E, Leppavirta J, Poyhonen M, Peltonen S, Peltonen J (2018) Prevalence of neurofibromatosis type 1 in the Finnish population. Genet Med 20(9):1082-1086. https://doi.org/ 10.1038/gim.2017.215

15. Khong PL, Goh WH, Wong VC, Fung CW, Ooi GC (2003) MR imaging of spinal tumors in children with neurofibromatosis 1. AJR Am J Roentgenol 180(2):413-417. https://doi.org/10.2214/ ajr.180.2.1800413

16. Khosrotehrani K, Bastuji-Garin S, Riccardi VM, Birch P, Friedman JM, Wolkenstein P (2005) Subcutaneous neurofibromas are associated with mortality in neurofibromatosis 1: a cohort study of 703 patients. Am J Med Genet A 132A(1):49-53. https://doi. org/10.1002/ajmg.a.30394

17. Lammert M, Friedman JM, Kluwe L, Mautner VF (2005) Prevalence of neurofibromatosis 1 in German children at elementary school enrollment. Arch Dermatol 141(1):71-74. https://doi.org/ 10.1001/archderm.141.1.71

18. McKeever K, Shepherd CW, Crawford H, Morrison PJ (2008) An epidemiological, clinical and genetic survey of neurofibromatosis type 1 in children under sixteen years of age. Ulster Med J 77(3):160-163

19. Neville HL, Seymour-Dempsey K, Slopis J, Gill BS, Moore BD, Lally KP, Andrassy RJ (2001) The role of surgery in children with neurofibromatosis. J Pediatr Surg 36(1):25-29. https://doi.org/10. 1053/jpsu.2001.19996

20. Noble F, Kornberg AJ, Elder JE, Delatycki MB (2007) Retrospective analysis of patients attending a neurofibromatosis type 1 clinic. J Paediatr Child Health 43(1-2):55-59. https://doi.org/10. 1111/j.1440-1754.2007.01003.x

21. Orraca M, Morejon G, Cabrera N, Menendez R, Orraca O (2014) Neurofibromatosis 1 prevalence in children aged 9-11 years, Pinar del Rio Province. Cuba MEDICC Rev 16(3-4):22-26

22. Pociello R, Noviello MR, Giustini S, Villari P, Divona L, Calvieri $\mathrm{S}$ (2005) NF1: early detection program in roman scholastic institutes. Derm Clin 25(1):23-26

23. Prada CE, Rangwala FA, Martin LJ, Lovell AM, Saal HM, Schorry EK, Hopkin RJ (2012) Pediatric plexiform neurofibromas: impact on morbidity and mortality in neurofibromatosis type 1. J Pediatr 160(3):461-467. https://doi.org/10.1016/j.jpeds.2011. 08.051

24. Hemenway M Prevention of plexiform neurofibroma rapid regrowth following surgical resection. In: NF conference, Washington, D.C., June 10-13 2017.

25. Needle MN, Cnaan A, Dattilo J, Chatten J, Phillips PC, Shochat S, Sutton LN, Vaughan SN, Zackai EH, Zhao H, Molloy PT (1997) Prognostic signs in the surgical management of plexiform neurofibroma: the Children's Hospital of Philadelphia experience, 1974-1994. J Pediatr 131(5):678-682. https://doi.org/10.1016/ s0022-3476(97)70092-1

26. Canavese F, Krajbich JI (2011) Resection of plexiform neurofibromas in children with neurofibromatosis type 1. Journal of Pediatric Orthopaedics 31(3):303-311

27. Gross AM SPRINT: Phase II study of the MEK $1 / 2$ inhibitor selumetinib (AZD6244, ARRY-142886) in children with neurofibromatosis type 1 (NF1) and inoperable plexiform neurofibromas (PN). In: Joint Global Neurofibromatosis Conference; Paris, November 2-6 2018.

28. Lai JS, Jensen SE, Charrow J, Listernick R (2019) Patient reported outcomes measurement information system and quality of life in neurological disorders measurement system to evaluate quality of life for children and adolescents with neurofibromatosis type 1 associated plexiform neurofibroma. J Pediatr 206:190-196. https://doi.org/10.1016/j.jpeds.2018.10.019

29. Wolters P Using Patient-reported outcomes (PROs) to assess pain and classify morbidity in neurofibromatosis 1 (NF1) clinical trials for plexiform neurofibromas (PNs): baseline data from the pediatric phase II selumetinib trial. In: NF conference, Washington, D.C., June 10-13 2017.

30. Wolters P Propsective patient-reported outcomes (PROs) document clinical benefit in children with neurofibromatosis type 1 (NF1) and inoperable plexiform neurofibromas (PNs) on SPRINT: a phase II trial of the MEK 1/2 inhibitor selumetinib (AZD6244, ARRY-142886). In: Joint Global Neurofibromatosis Conference, Paris, November 2-6 2018.

31. Wolters PL, Burns KM, Martin S, Baldwin A, Dombi E, ToledoTamula MA, Dudley WN, Gillespie A, Widemann BC (2015) Pain interference in youth with neurofibromatosis type 1 and plexiform neurofibromas and relation to disease severity, socialemotional functioning, and quality of life. Am J Med Genet A 167A(9):2103-2113. https://doi.org/10.1002/ajmg.a.37123

32. Gross A, Wolters P, Baldwin A, Dombi E, Fisher MJ, Weiss B, Kim A, Blakeley J, Whitcomb P, Holmblad M, Maritin S, Roderick MC, Paul SM, Therrien J, Heisey K, Doyle A, Smith M, Glod J, Steinberg S, Widemann BC (2018) Sprint: phase II study of the MEK 1/2 inhibitor selumetinib (AZD6244, ARRY$142886)$ in children with neurofibromatosis type 1 (NF-1) and inoperable plexiform neurofibromas (PN). Neuro-Oncology 20(suppl_2):i143-i144

33. Canavese F, Krajbich J (2011) Resection of plexiform neurofibromas in children with neurofibromatosis type 1. J Pediatr Orthop 31(3):303-11

34. Dagalakis U, Lodish M, Dombi E, Sinaii N, Sabo J, Baldwin A, Steinberg SM, Stratakis CA, Widemann BC (2014) Puberty and plexiform neurofibroma tumor growth in patients with neurofibromatosis type I. J Pediatr 164(3):620-624

35. Liberati A, Altman DG, Tetzlaff J, Mulrow C, Gotzsche PC, Ioannidis JP, Clarke M, Devereaux PJ, Kleijnen J, Moher D (2009) The PRISMA statement for reporting systematic reviews and meta-analyses of studies that evaluate healthcare interventions: explanation and elaboration. BMJ 339:b2700. doi:https://doi.org/ 10.1136/bmj.b2700

36. Burns PB, Rohrich RJ, Chung KC (2011) The levels of evidence and their role in evidence-based medicine. Plast Reconstr Surg 128(1):305

Publisher's note Springer Nature remains neutral with regard to jurisdictional claims in published maps and institutional affiliations. 